\title{
Adherence to Guidelines for Cardiac Catheterization Referrals and Secondary Prevention Strategies in Patients with Non-ST Segment Elevation Acute Coronary Syndromes
}

Michelle J. Haroun MD, Anjali Shroff MD, Joshua J. Manolakos MD, Madhu K. Natarajan MD MSc, John You MD MSc, Ameen Patel MD

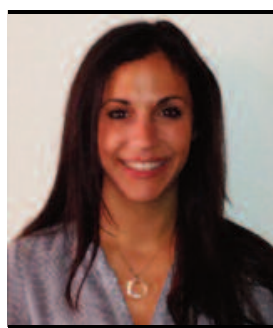

\section{About the Authors}

Michelle J. Haroun (left) is currently enrolled in the cardiology fellowship training program at McMaster University in Hamilton, Ontario. She received her undergraduate medical degree at McMaster University in 2009, and completed her Internal Medicine residency training at McMaster University in 2012. Anjali Shroff, Joshua J. Manolakos, Madhu K. Natarajan, John You, and Ameen Patel are members of the Department of Medicine at McMaster University, Hamilton, Ontario. Correspondence can be directed to michelleharoun@gmail.com.

\section{Summary}

Background: Previous studies have demonstrated higher referral rates for invasive procedures among patients admitted with acute coronary syndromes (ACS) to hospitals with catheterization facilities compared to those without. Studies have also reported underuse of evidence-based medical therapies and cardiac rehabilitation programs post myocardial infarction. We evaluated referral patterns for cardiac catheterization and use of secondary prevention strategies in current practice.

Methods: We conducted a retrospective study of 397 patients with non-ST segment elevation ACS, comparing angiography referrals at a hospital with on-site catheterization facilities (Site A, $n=194$ ) versus a hospital without (Site $\mathrm{B}, n=203$ ). We also recorded the use of secondary prevention strategies including discharge medications, referrals to smoking cessation programs and cardiac rehabilitation.

Results: There was no significant effect of on-site angiography on the decision to manage patients invasively (adjusted OR for on-site angiography 1.49 95\% CI 0.92-2.44, $p=.11$ ), or wait times for cardiac catheterization (Site A 1.9 days vs. Site B 2.2 days, difference -0.3 days, $95 \%$ CI -0.83 to $0.55, p=.70$ ). However, at the time of hospital discharge, less than $70 \%$ of patients were prescribed dual antiplatelet therapy and only $13 \%$ of patients were referred for cardiac rehabilitation.

Conclusion: These observations suggest that in contemporary practice in a Southern Ontario community, the availability of on-site percutaneous coronary intervention does not influence referral rates or wait times for cardiac catheterization. However we did observe significant underuse of cardiac rehabilitation programs and certain medical therapies. This suggests that despite improvements in access to invasive procedures, there remain important gaps in secondary prevention of coronary artery disease, which represent opportunities to improve quality of care in these patients. 


\section{Résumé}

Contexte : Des études montrent que le taux de patients souffrant d'un syndrome coronarien aigu (SCA) dirigés vers des procédures invasives est plus élevé dans les hôpitaux disposant de salles de cathétérisme que dans les autres. Des recherches montrent également que les thérapies basées sur les preuves sont sous-utilisées, de même que les programmes de réadaptation cardiaque suivant un infarctus du myocarde. Nous avons évalué les pratiques actuelles quant à l'orientation des patients vers le cathétérisme cardiaque et à l'utilisation de stratégies de prévention secondaire.

Méthodologie : Nous avons réalisé une étude rétrospective sur 397 patients présentant un ACS non ST+; nous avons comparé le taux de patients envoyés en angiographie dans un hôpital avec salle de cathétérisme ( site A, $n=194$ ) et dans un hôpital sans salle de cathétérisme (site $\mathrm{B}$, $n=203$ ). Nous avons également étudié le recours à des stratégies de prévention secondaire, dont la prescription de médicaments à la sortie de l'hôpital et l'orientation vers des programmes de cessation du tabagisme et de réadaptation cardiaque.

Résultats : La présence d'une salle d'angiographie sur place n'a aucun effet significatif sur la décision d'utiliser une technique invasive (OR ajusté pour l'angiographie sur place 1,49 $95 \%$ CI $0,922,44, p=0,11)$, ou sur le temps d'attente avant un cathétérisme cardiaque $(1,9$ jour au site $\mathrm{A}$ et 2,2 jours au site $\mathrm{B}$, différence de 0,3 jour, $95 \%$ CI $0,830,55, p=0,70$ ). Cependant, à leur sortie de l'hôpital, moins de $70 \%$ des patients se sont vu prescrire un traitement antiplaquettaire double, et seulement $13 \%$ des patients ont été orientés vers un programme de réadaptation cardiaque.

Conclusion : Ces observations laissent croire que dans le cadre des pratiques actuelles d'une communauté du sud de l'Ontario, la possibilité d'effectuer sur place une intervention coronarienne percutanée n'a pas d'influence sur le taux de patients dirigés vers le cathétérisme cardiaque, ni sur le temps d'attente. Nous avons cependant observé une sous-utilisation importante des programmes de réadaptation cardiaque et de certaines thérapies. Cela laisse croire que malgré un accès amélioré aux procédures invasives, il reste des lacunes importantes à combler en matière de prévention secondaire des coronaropathies afin d'améliorer la qualité des soins aux patients.

$\mathrm{P}$ atients with non-ST segment elevation acute coronary syndromes (ACS) represent a heterogeneous group with varying risk of death and ischemic complications. These patients should be risk stratified to determine the need for early revascularization versus a conservative approach with medical therapy alone. ${ }^{1}$ The Thrombolysis in Myocardial Infarction (TIMI) Risk score is a validated prognostication tool, which has shown to predict the risk of death and ischemic complications in patients with acute coronary syndrome. ${ }^{2}$ Despite the availability of risk stratification tools, there is wide variability in clinical practice regarding the decision to invasively manage patients with non-ST elevation ACS. ${ }^{3}$ Several studies have examined the impact of geographic location and availability of on-site angiography on referral patterns. These studies have consistently shown that patients admitted with ACS are more likely to undergo coronary angiography, and experience shorter wait times, if they are admitted to a hospital with on-site cardiac catheterization facilities. ${ }^{3-5}$ Studies have also shown that risk stratification tools are underutilized in the selection of an invasive versus conservative strategy. ${ }^{6}$

To our knowledge, there are no recent studies that have compared the referral patterns for cardiac catheterization at hospitals with and without catheterization facilities, according to initial risk assessment (e.g., Thrombolysis in Myocardial Infarction [TIMI] Risk score). The primary objective of this study was to examine the pattern of angiogram referrals in patients with non-ST elevation ACS based on the TIMI risk score at sites with and without catheterization facilities.

Despite recent advances in revascularization procedures, medical therapy remains as the cornerstone of treatment for coronary artery disease (CAD). Optimal use of medical therapy and risk factor modification strategies are still likely to be the most effective interventions with respect to mortality reduction in patients with $\mathrm{CAD} .{ }^{6} \mathrm{~A}$ secondary objective of this study was 
Table 1. Baseline characteristics of patients at Site A (on-site cardiac catheterization) and Site B (no on-site cardiac catheterization)

\begin{tabular}{llll}
\hline Patient Demographics & Site A & Site B & P value \\
\hline Number of patients & 194 & 203 & \\
\hline Mean age (SD) & $66.1(13.3)$ & $68.4(12.6)$ & .08 \\
\hline Median age & 67 & 70 & .09 \\
\hline Number of females & $81(41.8 \%)$ & $101(49.8 \%)$ & .13 \\
\hline Median TIMI score* & 3 & 3 & .19 \\
\hline Known coronary artery disease & $123(63.4 \%)$ & $108(53.2 \%)$ & .05 \\
\hline Previous cardiac catheterization & $97(50.0 \%)$ & $68(33.5 \%)$ & .003 \\
\hline Previous percutaneous coronary Intervention & $56(28.9 \%)$ & $23(11.3 \%)$ & $<.001$ \\
\hline Previous coronary artery bypass graft & $34(17.5 \%)$ & $23(11.3 \%)$ & .12 \\
\hline Hypertension & $142(73.2 \%)$ & $150(73.9 \%)$ & .60 \\
\hline Diabetes & $73(37.6 \%)$ & $69(34.0 \%)$ & .70 \\
\hline Family history & $51(26.3 \%)$ & $32(15.8 \%)$ & .01 \\
\hline Dyslipidemia & $133(68.6 \%)$ & $122(60.1 \%)$ & .10 \\
\hline Current smoker & $47(24.2 \%)$ & $43(21.2 \%)$ & .26 \\
\hline Congestive heart failure & $18(9.3 \%)$ & $30(14.8 \%)$ & .12 \\
\hline ECG changes & $26(13.4 \%)$ & $34(16.7 \%)$ & .33 \\
\hline Troponin positive & $38(19.6 \%)$ & $76(37.4 \%)$ & $<.001$ \\
\hline Median creatinine & 79.0 & 78.0 & .55
\end{tabular}

$\mathrm{SD}=$ standard deviation; $\mathrm{TIMI}=$ thrombolysis in myocardial infarction.

Table 2. Predictors of referrals for cardiac catheterization

\begin{tabular}{|c|c|c|c|c|}
\hline & $\begin{array}{l}\text { Odds Ratio } \\
(95 \% \mathrm{Cl})\end{array}$ & $P$ value & $\begin{array}{l}\text { *Adjusted Odds Ratio } \\
(95 \% \mathrm{Cl})\end{array}$ & $P$ value \\
\hline ECG changes & $6.87(3.52-13.43)$ & $<.0001$ & $5.44(2.29-12.95)$ & $<.0001$ \\
\hline Troponin + & $3.90(2.46-6.18)$ & $<.0001$ & $3.91(2.10-7.27)$ & $<.0001$ \\
\hline $\begin{array}{l}\text { Cardiology consult or } \\
\text { Cardiology MRP }\end{array}$ & $3.78(2.36-6.05)$ & $<.0001$ & $2.85(1.69-4.80)$ & $<.0001$ \\
\hline TIMI risk & $1.49(1.27-1.74)$ & $<.0001$ & $1.24(1.02-1.52)$ & .03 \\
\hline Site (on-site PCl available) & $1.32(0.88-1.81)$ & .18 & $1.49(0.92-2.44)$ & .11 \\
\hline Age & $0.99(0.98-1.01)$ & .35 & $1.00(0.97-1.03)$ & .87 \\
\hline Gender (females) & $0.51(0.34-0.77)$ & .001 & $0.64(0.40-1.02)$ & .06 \\
\hline Prior $\mathrm{PCl}$ or $\mathrm{CABG}$ & $1.25(0.82-1.91)$ & .298 & -- & -- \\
\hline Known CAD & $1.11(0.74-1.66)$ & .62 & -- & -- \\
\hline Prior cardiac catheterization & $1.01(0.67-1.51)$ & .975 & -- & -- \\
\hline Serum creatinine & $0.99(0.99-1.00)$ & .24 & -- & -- \\
\hline
\end{tabular}

*Adjusted for age, gender, hospital site, TIMI risk, presence of ECG changes, troponin rise and involvement of Cardiologist (consult or most responsible physician)

$\mathrm{CABG}=$ coronary artery bypass graft; $\mathrm{CAD}=$ coronary artery disease; $\mathrm{MRP}=$ myeloid-related protein; $\mathrm{PCl}=$ percutaneous coronary intervention. to investigate adherence to current guidelines for secondary prevention including use of evidence-based medical therapies, referrals to cardiac rehabilitation and smoking cessation programs. ${ }^{1}$

\section{Methods \\ Study Setting}

The study was conducted at two academic teaching hospitals in Hamilton, Ontario: Hamilton General Hospital (Site A) which has on-site catheterization facilities and St. Joseph's Healthcare (Site B) which does not. This study was approved by the Hamilton Health Sciences and St. Joseph's Healthcare Research Ethics Boards.

\section{Patient Population}

We performed a retrospective study of consecutive patients admitted to the two hospitals with a diagnosis of unstable angina (UA) or non-ST elevation myocardial infarction (NSTEMI) between January 2009 and October 2010. To investigate the impact of on-site cardiac catheterization availability on clinical decisions, patients were divided according to the presence (Site A) or absence (Site B) of such facilities at the admitting hospital. We included patients over the age of 18 years who had an emergency department (ED) diagnosis of ACS, NSTEMI, or UA. Exclusion criteria included: an ED diagnosis of ST elevation myocardial infarction (STEMI); ischemia refractory to nitroglycerin infusion; congestive heart failure $(\mathrm{CHF})$ refractory to medical therapy; cardiogenic shock; patient refusal of cardiac catheterization; physician decision not to refer for cardiac catheterization based on patient comorbidities. 
Table 3: Rates of non-invasive testing, cardiac catheterization, and revascularization stratified by TIMI risk score

\begin{tabular}{|c|c|c|c|c|c|c|c|c|c|}
\hline & \multicolumn{3}{|c|}{ Low Risk (0-2) } & \multicolumn{3}{|c|}{ Intermediate Risk (3-4) } & \multicolumn{2}{|c|}{ High Risk (5-6) } & \multirow[b]{2}{*}{$p$} \\
\hline & Site A & Site B & $p$ & Site A & Site B & $p$ & Site A & Site B & \\
\hline Number of patients & 67 & 78 & & 102 & 89 & & 25 & 35 & \\
\hline Non-invasive study & $27(40.2 \%)$ & $20(25.6 \%)$ & .37 & $13(12.7 \%)$ & $14(15.7 \%)$ & .64 & $2(8.0 \%)$ & $4(11.4 \%)$ & .42 \\
\hline Cardiac catheterization & $18(26.9 \%)$ & $29(37.2 \%)$ & .02 & $55(53.9 \%)$ & $29(32.6 \%)$ & .001 & $18(72 \%)$ & $23(65.7 \%)$ & .21 \\
\hline${ }^{*} \mathrm{PCl}$ & $5(27.8 \%)$ & $14(48.3 \%)$ & .003 & $26(47.3 \%)$ & $10(34.5 \%)$ & .007 & $7(38.9 \%)$ & $6(26.1 \%)$ & 1.0 \\
\hline${ }^{*} \mathrm{CABG}$ & $1(5.6 \%)$ & $2(6.9 \%)$ & .58 & $5(9.1 \%)$ & $5(17.2 \%)$ & 1.0 & $8(44.4 \%)$ & $5(21.7 \%)$ & .70 \\
\hline *Low risk coronary anatomy & $9(50 \%)$ & $10(34.5 \%)$ & .57 & $16(29.1 \%)$ & $11(37.9 \%)$ & .40 & $1(5.6 \%)$ & $2(8.7 \%)$ & .60 \\
\hline
\end{tabular}

(normal or mild CAD

*Percentage of patients undergoing angiography

$\mathrm{CABG}=$ coronary artery bypass graft; $\mathrm{CAD}=$ coronary artery disease; $\mathrm{PCl}=$ percutaneous coronary intervention.

Table 4. Frequency of medication use at the time of discharge from each hospital site

\begin{tabular}{llll}
\hline Medication & $\begin{array}{l}\text { Site A } \\
(\boldsymbol{n}=81)\end{array}$ & $\begin{array}{l}\text { Site B } \\
(\boldsymbol{n}=115)\end{array}$ & $\boldsymbol{P}$ value \\
\hline Aspirin & $68(89.5 \%)$ & $95(91.3 \%)$ & .80 \\
\hline Clopidogrel & $49(64.5 \%)$ & $69(66.3 \%)$ & .87 \\
\hline Beta blocker & $62(81.6 \%)$ & $77(74.0 \%)$ & .36 \\
\hline Statin & $70(92.1 \%)$ & $91(87.5 \%)$ & .46 \\
\hline Ace inhibitor & $45(59.0 \%)$ & $66(63.5 \%)$ & .54 \\
\hline $\begin{array}{l}\text { Angiotensin Receptor } \\
\text { blocker }\end{array}$ & $9(11.8 \%)$ & $18(15.7 \%)$ & .40 \\
\hline
\end{tabular}

\section{Data Collection}

Data was abstracted from medical records by four trained investigators. Admission data included patient demographics, cardiac risk factors, the presence of ECG changes $(\geq 0.5 \mathrm{~mm} \mathrm{ST}$ segment deviation) and cardiac biomarkers (troponin $\mathrm{T}$ ), serum creatinine, and admission medications. We used the chartabstracted data to calculate the TIMI risk score for each patient.

We recorded referrals for non-invasive testing, cardiac catheterization and revascularization procedures. Wait times for cardiac catheterization and duration of hospital stay were recorded. The use of secondary prevention strategies was evaluated by recording discharge medications and referrals to cardiac rehabilitation as well as smoking cessation programs.

To ensure concordance between data extractors, all four investigators extracted data from a training set of 30 charts. Cohen's kappa coefficient for the TIMI risk score was 0.77 .

\section{Statistical Analysis}

We compared patient data at the two sites using the Student's $t$ test for continuous variables and the Fishers' exact test for

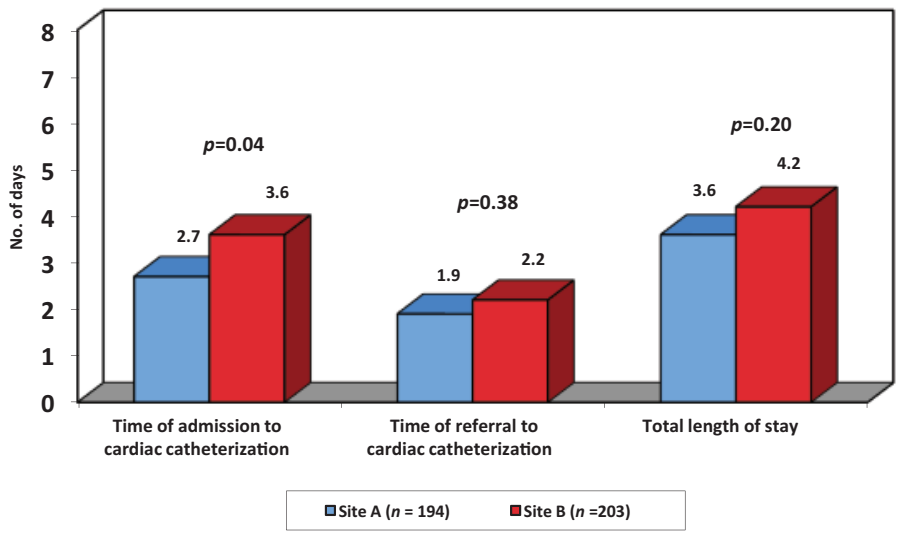

Figure 1. Wait times for angiography and total length of stay according to site.

categorical variables. Referral rates for cardiac catheterization were compared across low (0-2), intermediate (3-4) and high (5-7) TIMI risk groups between the two sites using the Student's $t$ test.

We analyzed univariable associations of hospital site and cardiac catheterization referrals, TIMI risk score, serum creatinine, prior history of CAD, prior cardiac catheterization, and prior revascularization procedures. We used logistic regression to perform a multivariate analysis in order to evaluate the independent association between hospital site and angiogram referrals.

\section{Results}

\section{Patient Population}

A total of 397 patients were included in the study. Overall, patients at the two sites had a similar risk profile (median TIMI score of 3 at each site). The groups at each site were similar with respect to age, gender, and most risk factors for CAD (Table 1). However, patients admitted to Site A had higher rates of known $\mathrm{CAD}$ and prior revascularization procedures, while patients 
admitted to site B had higher rates of positive cardiac biomarkers.

\section{Predictors of Cardiac Catheterization Referrals}

Overall, availability of on-site cardiac catheterization did not have a significant impact on catheterization referral rates (Table 2). The strongest predictors of cardiac catheterization referrals were the presence of ECG changes (adjusted OR 5.44, 95\% CI 2.29$12.95, p<.0001$ ) and positive cardiac biomarkers (adjusted OR $3.91,95 \%$ CI $2.10-7.27 p<.0001)$.

\section{Cardiac Catheterization Referrals Stratified by TIMI Risk Score}

An invasive approach was selected in the majority of high-risk patients (TIMI $>4$ ), (Site A $72.0 \%$ vs. Site B $65.7 \%, p=.21$ ), with very few high-risk patients referred for noninvasive testing (Site A $8.0 \%$ vs. Site B $11.4 \%, p=0.42$ ) (Table 3). Low risk patients (TIMI <3) were managed conservatively in most cases, but were more often referred for angiography at the site without PCI available (Site A $26.9 \%$ vs. Site B $37.2 \%, p=.03$ ). Intermediate risk patients (TIMI 3-4) were much more likely to be referred for angiography if admitted to the hospital with on-site catheterization facilities (Site A $53.9 \%$ vs. Site B 32.6\%, $p=.001$ ).

\section{Wait Times}

Among patients referred for cardiac catheterization, there was no difference in the time delay from referral date to the procedure date between the two sites (1.9 days at Site A vs. 2.2 days at Site $\mathrm{B}, p=.38$ ) (Figure 1). Overall, there was a trend towards a shorter length of stay for patients admitted to the hospital with on-site cardiac catheterization facilities, but this was not statistically significant (3.6 days at Site A vs. 4.2 days at Site B, $p=.20$ ).

\section{Use of Secondary Prevention Strategies}

In our study, $89.5 \%$ and $91.3 \%$ of patients were discharged home on aspirin therapy from Site A and Site B, respectively. However, only $64.5 \%$ and $65.3 \%$ of patients were discharged on clopidogrel. The frequencies of medication use at the time of discharge are shown in Table 4.

Approximately $23 \%$ of included patients were identified as current smokers. However, only $12.8 \%$ (Site A) and 2.3\% (Site B) of current smokers were referred to smoking cessation programs. Referral rates to cardiac rehabilitation programs were $11.5 \%$ and $14.5 \%$ at Site A and Site B respectively.

\section{Discussion}

In both the univariate analysis and adjusted analyses, we found no association between hospital site and the decision to refer patients for angiography. When stratified by TIMI risk group, most low risk patients were appropriately managed conservatively, while the majority of high-risk patients underwent angiography. Wait times for cardiac catheterization and total length of hospital stay did not differ significantly between sites. Our findings contrast with those of previous studies, which have identified hospital site as an important predictor of angiography referrals and total length of stay. ${ }^{3}$ This may reflect the impact of regional referral strategies and recent efforts to reduce wait times by the Cardiac Care Network (CCN) of Ontario. This working group was established in an effort to improve patient access to centralized cardiac care across the province in the last twenty years.

Overall, use of medical therapies was high in our study population. The use of aspirin, beta-blockers and ACE inhibitors or ARBs demonstrated an improvement in adherence to guidelines compared to previous studies which demonstrated aspirin use in less than $80 \%$ of patients, and the use of statins and ACE inhibitors in less than $50 \%$ of patients at hospital discharge. ${ }^{7-9}$ Two-thirds of patients were prescribed dual antiplatelet therapy at the time of hospital discharge. Clopidogrel has been shown to reduce ischemic complications in patients with non ST-segment elevation ACS who have dynamic ECG changes, positive cardiac biomarkers or who undergo revascularization. ${ }^{10}$ Less than $50 \%$ of patients in our study met these clinical criteria and therefore more selective use of clopidogrel was likely appropriate.

With regards to non-pharmacological, secondary prevention strategies, referral rates to cardiac rehabilitation and smoking cessation programs were extremely low at both hospitals. Cardiac rehabilitation in patients post myocardial infarction has been shown to reduce recurrent ischemic events and cardiovascular mortality. ${ }^{11,12}$ The low referral rates observed in our study suggest there is a need for education regarding the efficacy and availability of supervised exercise programs in patients with CAD. This might represent an opportunity to improve the quality of care in ACS patients.

\section{Limitations}

Our study has limitations as a result of its retrospective design and relatively small sample size. However, it is unlikely that a larger sample size would have significantly altered the main observations of this study. We observed a trend towards higher rates of angiogram referrals at the centre with on-site angiography, but this did not reach statistical significance. Perhaps a larger study would have demonstrated this difference to be significant, with more patients being referred at hospitals with on-site facilities. With this in mind, our study did demonstrate significant underuse of certain secondary 
prevention strategies despite the limitations in sample size. Arguably, this message is of greater significance, as medical therapy is still the cornerstone of coronary artery disease management.

\section{Conclusion}

Our study showed that referrals for cardiac catheterization for patients with non-ST segment elevation ACS seem to be both timely and appropriate, regardless of availability of on-site cardiac catheterization. Use of evidence based medical therapies in ACS has improved in comparison to previous reports. However, cardiac rehabilitation and smoking cessation programs were significantly underutilized. Although there have been significant improvements in access to invasive procedures, there remain important gaps in secondary prevention strategies which represent important opportunities to improve quality of care in these patients.

\section{Funding}

This study was supported by an unrestricted grant from the Division of General Internal Medicine at McMaster University, Hamilton ON.

\section{References}

1. Anderson J, Adams C, Antman E et al. ACC/AHA 2007 guidelines for the management of patients with unstable angina/non-ST-elevation myocardial infarction: a report of the American College of Cardiology/American Heart Association Task Force on Practice Guidelines. J Am Coll Cardiol 2007;50:1157.
2. Antman E, Cohen M, Bernink P, et al. The TIMI risk score for unstable angina/Non-ST elevation MI. JAMA 2000;284(7):835-42.

3. Yusuf S, Flather M, Pogue J, Hunt D, Varigos J, Piegas L, et al. Variations between countries in invasive cardiac procedures and outcomes in patients with suspected unstable angina or myocardial infarction without initial ST elevation. OASIS (Organisation to Assess Strategies for Ischaemic Syndromes) Registry Investigators. Lancet 1998;352:507-14.

4. Alter DA, Naylor D, Austic PC, Chan BJ, Tu JV. Geography and service supply do not explain socioeconomic gradients in angiography use after acute myocardial infarction. CMAJ 2003;168 (3):261-4.

5. Singh N, Gupta M, Fell D, Gangbar E. Impact and inequity of inpatient waiting times for advanced cardiovascular services in community hospitals across the Greater Toronto Area. Can J Cardiol 1999;15(7):777-82.

6. Lee CH, Tan M, Yan AT, et al. Use of cardiac catheterization for non-STsegment elevation acute coronary syndromes according to initial risk. Arch Intern Med 2002;169:291-96.

7. Wijeysundera HC, Machado M, Farahati F, et al. Association of temporal trends in risk factors and treatment uptake with coronary heart disease mortality, 1994 - 2005. JAMA 2010;303(18):1841-47.

8. Simpson E, Beck C, Richard H, Eisenberg MJ, Pilote L. Drug prescriptions after acute myocardial infarction: dosage, compliance, and persistence. Am Heart J 2003;145:438-44.

9. Tu JV, Donovan LR, Wang DS, et al. Effectiveness of Public Report Cards for Improving Quality of Care (The EFFECT study: a Randomized Trial). JAMA 2009;302(21):2330-37.

10. Yusuf S, Zhao F, Mehta SR, et al. Effects of clopidogrel in addition to aspirin in patients with acute coronary syndromes without ST-segment elevation. N Engl J Med 2001;345 (7):494-502.

11. Heran BS, Chen JM, Ebrahim S, et al. Exercise-based cardiac rehabilitation for coronary heart disease. Cochrane Database Syst Rev 2011. Jul 6; (7):CD001800.

12. Lawler PR, Filion KB, Eisenberg MJ. Efficacy of exercise-based cardiac rehabilitation post myocardial infarction: a systematic review and metaanalysis of randomized controlled trials. Am Heart J 2011;162(4):571-84. 